\title{
Role of users of health care in achieving a quality service
}

\author{
Anthony Hopkins, John Gabbay, Julia Neuberger
}

The modern practice of medicine recognises that patients are not merely passive recipients of advice and procedures from health professionals but that they have an active role in their own care. For there to be a full assessment of the quality of care, contributions are needed from at least three parties: the doctor, other health professionals, and the patient. Sometimes there will be other interested parties - for example, parents in the case of young children and carers in the case of those who are helping to support people with chronic mental or physical illness. Potential patients are also interested in the quality of their local services. In this paper the term "user" is taken to include not only present and past patients but also potential users of health services - that is, the general public. The interests of each of these three groups is not necessarily always the same.

The purpose of this paper is to analyse the contribution that users can make to clinical audit, extending the observations made by Donabedian in 1992 in his Lichfield lecture. ${ }^{1}$ In this he assigned three principal roles to users of care, as follows.

- As definers of quality, evaluating quality, and providing information that allows others to evaluate quality

- As targets of quality assurance, by which he referred to their role as partners or "coproducers" of care

- As reformers of care, emphasising their role in improving healthcare systems.

Since that lecture there have been other

Research Unit, Royal London NW1 4LE Anthony Hopkins, director

Wessex Institute of Public Health Medicine, University of Southampton, Southampton General Hospital,
Southampton SO9 4XY John Gabbay, professor

Camden and Islington Community Health Services NHS Trust, National Temperance Hospital

Lospital,

Jundia Neuberger, chairperson

Correspondence to: Dr A Hopkins, Research Unit, Royal College of Physicians, 11 St Andrew's Place, Regents Park London NW1 4LE

Accepted for publication 15 November 1994 to the healthcare system. Furthermore, governments can be elected on the promises of health reform - for example, the Clinton adminis- tration in the United States - without it being clear what the reforms are likely to be.

\section{LOCAL HEALTH SERVICES}

Users of health services should be able to have a major say in how their local health services are delivered. District health authorities and family health services authorities in the United Kingdom have a responsibility to define the health needs of their local populations and to commission or purchase health services to meet those needs. The structure suggests that the purchasers should represent the users' interests, but it is difficult to see how they can do so without much closer links into the communities on whose behalf they are purchasing care. Indeed, there is increasing concern that the appointment of political nominees to health authorities and to chair NHS trusts makes those health authorities and trusts less accountable to users than any electoral system. Kaletsky wrote: "The logic of consumer sovereignty points to direct elections for local health authorities, school governors, police chiefs, and even public utility regulators. Such detailed accountability may seem unimaginable in our elective dictatorships, but is common in America and many other genuinely democractic countries. ${ }^{5}$ "

The introduction of community health councils in the United Kingdom in 1974 recognised the need for more user participation in the old style NHS. Statute requires that these councils be consulted about various local decisions such as the closure of a hospital. Some councils have been successful in pressing for the development of local services or for the alteration in emphasis in the delivery of local services. However, there has been concern that despite all attempts some community health councils are not representative of their local populations. The Minister of Health in the United Kingdom stated that he wanted community health councils to work out "new and more effective relationships" with local purchasers, ${ }^{6}$ but it remains unclear how this is to be done. ${ }^{7}$ The Patients Association in the United Kingdom has identified a need for training for lay participation in health and has suggested ways of empowering lay people to alter the structure of their local health services. ${ }^{8}$ The publication of Local Voices ${ }^{9}$ underlines the need to involve local people in purchasing activities. An additional concern is that identifying and meeting health needs may be determined by health professionals rather than by users of health services. This may account for the emphasis, until very recently, on acute 
hospital care rather than on care in the community.

\section{Local priorities for health services}

Community health councils are in something of a dilemma. Should they attempt to represent the public's views when health authorities are considering local priorities and risk legitimising decisions to leave some needs unmet? The alternative is not to participate in "rationing," thereby forgoing the chance to influence local services and perhaps calling into question the very need for their existence. ${ }^{10}{ }^{11}$ It seems to us that involving the public in setting priorities, which is, in effect, setting the structure of the health service they wish to see, requires greater intellectual development and research than these issues have so far been afforded. The methodological issues have been barely touched, and we note Ham's comment that public choice is influenced by "the way in which questions are framed." 12 We are concerned that there should be research and discussion into better ways of maintaining democratic choice in an important component of our social system. The debate should be a continuous one. Possibilities include open meetings, telephone interviews, door to door surveys, and small groups invited to "focus" on one particular tranche of issues before wider debate. All this may help build an ethical consensus, when choices are often so painful.

Perhaps the best known example of how users of health services have been asked to try and influence the local structure of their services is the Oregon experiment. As this has been so extensively written about in recent years, (see reference 13) we do not discuss its methods further, beyond noting that attempts were made to involve the local population in decisions about setting standards for what the state health system would fund in future. The complexities of the project are indicated not only by concerns that the local meetings may not have been truly representative of the population but also by the necessary intervention by legislators and health professionals to rationalise the final rankings of what should and should not be funded.

Ham reviewed attempts by six district health authorities in the United Kingdom to set local priorities for health care and the degree to which the local population was involved in the discussions. ${ }^{12}$ We agree with what he writes: "Inevitably the process of setting priorities involves making judgements on the basis of incomplete information and evidence. These judgements are likely to be more soundly based and defensible if they have been exposed to public discussion." To his "incomplete information and evidence" we would add, "a lack of ethical consensus," illustrated by the example of coronary bypass surgery. The geographical variations in numbers of elderly people having such surgery suggests that different groupings of general practitioners, cardiologists, and cardiac surgeons view differently the "value" of this procedure. There is little doubt of the effectiveness of this treatment for older people in appropriate cases. ${ }^{14}$
INDIVIDUAL MEMBERS OF "PRESSURE GROUPS" Some physicians suggest that the representativeness of members of patient groups pressing for better services is in question. The research evidence, reviewed by Williamson, suggests that this is not so and such individuals do generally reflect the aspirations of what may be termed the "general members" of their groups. ${ }^{15}$

\section{Users' views on access to care}

Users of health services need to have information about the benefits of concentration of services. They need to know how much better it is, in terms of outcome, to travel nearly 115 $\mathrm{km}$ for radiotherapy at a tertiary centre rather than have less high technology care at a familiar hospital close to home. ${ }^{16}$ This example illustrates how a clearer definition of the rights of users of health services is needed in relation to contracts made by the health authority in the area in which users reside. Are the wishes of the local population taken sufficiently into account when deciding that a procedure should be undertaken in a tertiary care centre in a district far removed from the local users' place of residence? The example also highlights the dearth of methods to assess the relative values of access and other aspects of the quality of care.

\section{Users and process of care}

DETERMINING EFFECTIVENESS OF CARE

Patients are naturally concerned that the treatments they receive should work. The efficacy of healthcare technologies is determined by randomised controlled trials. By their willing participation in such trials, users of health services have the primary role in determining the efficacy of treatments for future generations of patients. Recruiting patients to randomised controlled trials is not easy, not least because ethically the research physicians or surgeons have to be confident that at the time of randomisation there is no known benefit over and above the "control" intervention. If firm evidence of benefit already exists then, clearly, withholding the treatment from all patients would be unethical. Yet there must be some prior evidence of benefit, or the trial would not be instituted in the first place. Giving more information to patients before randomisation has led to a reduced rate of recruitment to many trials. Particular concern has been voiced about the growing section of the population with Alzheimer's disease and other degenerative disorders. Research is essential to improve care for his condition and to slow deterioration, but those with the disease are unlikely to be competent to give their consent to being entered into trials. ${ }^{17}$ These and other ethical and practical considerations have led to a suggestion that people should "sign on," as it were, for randomised controlled trials in certain major diseases at a time when they are free from symptoms.

DETERMINING TECHNICAL COMPETENCE

It is difficult for users of health services to be competent in judging the quality of the more 
technical aspects of medical care. To take an extreme example, they are unlikely to have an informed view about the different types of anastomosis that could be performed in arterial or bowel surgery. However, even in such technical cases, there will often be occasions in which users need information on which to base their choice.

Research evidence indicates that patients are reasonably well informed about what technically should be done in a consultation. For example, Davies and Ware video recorded simulated consultations that deliberately manipulated three different aspects of care (technical aspects, psychosocial aspects, and patient participation) for a repeat outpatient consultation for a "patient" with previously diagnosed angina. ${ }^{18}$ The quality of the technical aspects of care was rated by physicians and, separately, by lay people. The lay people rated significantly more favourably those interviews which were scripted to include necessary and sufficient history and items of physical examination than low technical quality consultations which omitted relevant and included irrelevant items. These results were obtained in the United States. In a less informed constituency people may be less able to rate the technical aspects of care.

In another study patients with tension headaches interviewed before their consultations with a neurologist had vague and ill formed ideas of what to expect. However, once in the consultation their expectations seemed to crystallise, and some patients were able to say why they were dissatisfied with some technical aspects of care - namely, what the neurologist did, such as the extent of the physical examination. However, many more patients were dissatisfied with communication and other interpersonal aspects. ${ }^{19} 20$

\section{CONFUSING QUANTITY OF CARE WITH QUALITY} OF CARE

There is evidence that at least some patients equate technical quality with quantity of care. Davies and Ware suggest that the proponents of this argument hold that consumers can be "seduced by the kind or number of tests and procedures received into believing that services provided were appropriate and well informed." ${ }^{18}$ Sox and his colleagues studied men with chest pain of a type considered on the basis of a clinical algorithm not to require tests to rule out a myocardial infarction. However, patients who were randomly assigned to have electrocardiography and measurement of their serum concentrations of creatine phosphokinase (which is raised if myocardial infarction had occurred) evaluated their overall care more favourably than did those who did not. ${ }^{21}$ Again, however, such observations are not generalisable to all clinical situations. The study on tension headaches found no significant relation between patient satisfaction and the extent of investigations performed. ${ }^{19}{ }^{20}$ We do not know how stable such observations are. That study was carried out in the early days of brain scanning, and the same results may not be found if it were repeated.
WHAT PEOPLE WANT: USERS' CHOICE OF INTERVENTION

We argue that the nearer to "normality" is the "medical" event experienced by a person, then the greater should be the input of the users of health services to determine the types of help provided. For example, users of maternal health services have been the dominant force in changing the practices of obstetric care in the past 20 years, so that expectant mothers are now offered a wide choice of birthing practices. Childbirth is an event experienced by most women; likewise, most of us grow old and require some sort of help in extreme old age. Users of health services should also be the arbiters of whether help, care, or support in such circumstances reaches acceptable standards. By this thesis, users should be the arbiters of good practice in a significant part of maternal care, in the care of elderly people, in the care of young children, and in health promotion and programmes designed to prevent illness.

On the other hand, a tension exists between what people want and the evidence for the clinical effectiveness of that want. An example might be language therapy after stroke, for which there is little evidence of effectiveness over and above support provided by volunteers. ${ }^{22}$ Another example is that of a patient with a tension headache requesting a brain scan from a neurologist, although the evidence suggests that scans are not an appropriate investigation in these circumstances. ${ }^{23}$ Physicians are placed in the front line in attempting to resolve the dilemma between acquiescing to what the patient wants (which may carry some significant clinical risk) and providing services of proven effectiveness. This issue is insufficiently considered in the present international "effectiveness initiatives."

\section{Users' views on outcomes of care}

Failure to recognise the different perspectives of health professionals and patients may lead to dissatisfaction unless health professionals take care to explain the reasons for trying to achieve the outcome they consider to be important. For example, after a minor stroke a patient's hand may well remain clumsy - a poor outcome. Neurologists know that no intervention is likely to alter that particular outcome, and their perspective is (if relevant) to succeed in helping the patient to stop smoking and to reduce high blood pressure. These are the best outcomes neurologists know that they can realistically achieve, even though they are not on the patient's agenda to any great extent. However, the patient's emphasis will probably be on physiotherapy, primarily in an attempt to improve the function of the hand. Technical motor function is improved only to a limited extent by physiotherapy. ${ }^{24}$ On the other hand, patients do gain from physiotherapy an increased sense of wellbeing and sense of self worth, equally valid outcomes that must be taken into account. $^{25}$

Users of health services also have a role in alerting health professionals to the fact that 
care which seems efficacious from a technical medical perspective may be ineffective from their perspective. One example might be the use of drugs to treat high blood pressure. Many drugs are efficacious in lowering blood pressure, but at the expense of unpleasant effects such as impotence and lethargy which make them less effective in everyday clinical practice, ${ }^{26}$ reflecting the wider point that the patient's and physician's perspective about the outcome for which each is striving may be different. The differences between consumer and professional standards in health care are explored by Williamson in her appropriately titled book, Whose Standards?. ${ }^{15}$

These disjunctions spill over into research. Randomised trials of interventions should include as end points outcomes that are important to patients, such as reducing shortness of breath during daily activity, avoiding being admitted to hospital for heart failure, or decreasing the risk of a heart attack. At present, some researchers use only technical outcome measures in trials, such as changes in lung function, measures of cardiac output, and a reduction in serum cholesterol concentration. Good examples of research into outcomes centred on the user perspective are that by Garratt and colleagues on the important outcomes for patients after operations on their varicose veins ${ }^{27}$ and the value of physiotherapy to stroke patients. ${ }^{25}$

\section{Users' involvement in audit}

USER GROUPS

Community health councils in the United Kingdom have been slow to ask their local providers to audit different aspects of care. ${ }^{28}$ However, commissioners of local care are now advised to retain $40 \%$ of the audit budget for activities which will presumably reflect their concerns - a proxy for the concerns of local users. $^{29}$

\section{INDIVIDUAL USERS}

Audit studies have already been published in which patient involvement has been suggested or tried. Devlin discussed the importance of patients' perceptions for surgical audit, ${ }^{30} \mathrm{a}$ view echoed in the work of Richardson and others who showed how perceptions of a hospital stay differed between the hospital doctors, nursing staff, family doctors and patients. ${ }^{31}$ In mental health Sharma also found an appreciable difference between those aspects of care rated most useful by patients and by nurses at a psychiatric hospital. ${ }^{32}$ Other studies in mental health are reviewed by Rogers and colleagues. ${ }^{33}$ In general practice Rashid and colleagues found significant disagreement between patients and their general practitioners about the doctors' ability to put patients at ease, to offer explanations and advice on treatment, and to allow expression of emotional feelings. ${ }^{34}$ Hares and colleagues showed how patients and health professionals rated differently aspects of diabetes care, ${ }^{35}$ and Taylor and colleagues explored patients' knowledge of their anticoagulant treatment and how this affects control. ${ }^{36}$
Users of health services must also be the preeminent arbiters of good quality practice in some areas in which they, and only they, can determine good practice, as illustrated in the following examples.

\section{Relief of pain}

Pain is a subjective experience, so patients must be the judge of whether their pain has been effectively relieved. Postoperative pain still seems to be inadequately managed on occasion. Research studies show that patientdirected management of postoperative pain is more effective than if nurses control dosage and intervals. In palliative care, too, patients should, as far as possible, control their own pain relief. Adequate relief of pain is a useful topic for clinical audit by a surgical or gynaecological firm or in palliative care, and a suggested protocol is available. ${ }^{37}$

\section{Courtesy}

If users of a health service think that they are not being treated courteously then no one can say that their perceptions are incorrect.

\section{Communication}

If patients fail to understand the nature of their illnesses and of the treatment planned, then the doctor or other health professional is likely to have failed to explain these matters in comprehensible terms. ${ }^{38}$ We argue also that consumers generally are the best judges of whether or not literature aimed at promoting health or at attracting people to services designed to prevent illness fulfil their purposes. Even at the simple level of package inserts for drugs in the United Kingdom, the manufacturers' information is often lamentably poor from the consumers' perspective. Switzerland and Sweden, two countries with very different political and cultural traditions, have shown that it is possible to get important information about drugs across in a user friendly way. In addition, in multiracial societies information must be made available in several languages, and at consultations an adequate interpreter should be present ${ }^{39}$ certainly a point for audit.

\section{Personal circumstances and choice}

Individual users need to alert their doctor or other health professional to important aspects of their own life which require consideration, and health professionals must be sensitive to these aspects of care. For example, there is good evidence that antiepileptic drugs after a first epileptic seizure prevent subsequent seizures. ${ }^{40}$ An epileptic schoolteacher, concerned that she may have a seizure in front of her class, might therefore wish to take such drugs. On the other hand, it would also be right for her doctor to tell her of the potential slight but definite effects of antiepileptic drugs on cognitive function, their potential teratogenetic effects, and the troublesome interaction of some antiepileptic drugs with oral contraceptives. The patient could then make an informed decision about whether to take the drugs or not. Users of health services are at 
present particularly concerned that the various treatment options for a condition are not appropriately displayed for their choice, with adequate information provided about the possible favourable and unfavourable outcomes of each choice.

\section{"Hotel" standards}

Users of health services are aware that hospitals are not luxury hotels, but, within resources available for health care, they are the arbiters in determining whether the cleanliness of a ward, the attractiveness of presentation of food, and many of the facilities within a ward are of an acceptable standard. Work in Bloomsbury showed the simplicity of collecting the views of patients about such aspects of care. ${ }^{41}$ However, many researchers believe that far more sophisticated methods are necessary to capture patients' feelings about clinical aspects of their care.

\section{Continuity and coordinated care}

Continuity and coordinated care, valued highly by users of health services, ${ }^{42}$ are likely to be increasingly threatened in hospitals since the numbers of hours worked by younger doctors has been reduced. Of necessity, this means that any hospital patient will encounter a larger number of junior medical staff. This change follows similar changes in the pattern of the organisation of nursing that occurred about 15 years ago, in response to which the nursing profession attempted to counter the perception of discontinuity by requiring that each patient be assigned a primary nurse.

Much patient dissatisfaction centres on the lack of coordination in care, so that, for example, a physiotherapy session may be scheduled at the same time as a consultant round, denying an opportunity for the patient to speak to the consultant. Perhaps even more important is the fragmentation of services across institutional boundaries. Patients are interested in their illness and its outcome, not in the institutional and administrative details of its management, which should occur almost invisibly behind their various contacts with health professionals. Increasing professional demarcations and the resulting fragmentation of care has resulted in the emergence of a new profession - the care manager - whose job is to integrate the care provided by different professional factions. The emergence of such posts is an indictment of interprofessional communication and of the present organisation of care.

\section{Professional accountability}

In the previous sections we have explored how to involve users more in clinical audit. In order to achieve change we have to consider how health professionals can be made more accountable to users of health care. Without such accountability, the involvement of users in audit will have little impact. Cultural changes in the developed world in the past 15 years have been associated with increased demands for professional accountability. This has not only affected the practice of medicine: there is wide discussion about the accountability of schoolteachers for the education of their pupils, and demands for increased openness in the legal profession. This has been reflected in the growth of pressure groups of consumers such as, in the United Kingdom, the Consumers' Association and the Patients Association. A recognition of the rights of users of centrally controlled services had led to the growth of the idea of the participative citizen, and the citizen's charter. Work by Wennberg and his colleagues in the United States ${ }^{43}$ and by McPherson, Coulter, and others in the United Kingdom ${ }^{44}$ have shown the extent of practice variations, which cannot be explained by variations in the type of patients treated and the severity of their disease. Users recognise that the very existence of such variation undermines the concept that doctors know the right and proper way to treat every disorder. New systems of accountability are under development. The entire NHS complaints system has recently been reviewed and simplified and more sensitive way of handling complaints proposed. ${ }^{45}$ The General Medical Council is considering new procedures for doctors whose clinical performance falls short of a reasonable professional standard. ${ }^{46}$ Perhaps more important is the recognition by the royal colleges that more formal systems of continuing medical education are likely to improve care. ${ }^{47}$ User groups are exerting some pressure for re-accreditation as a method of ensuring that health professionals remain up to date.

\section{The way forward}

We believe that users must be involved far more in discussions about health care, by helping choose measurable outcomes of care that are relevant to them, by participating in research studies, by commenting on research findings, and by discussing the allocation of resources to particular types of health care. Much of this will be unfamiliar to many users of health services, although those with chronic conditions have, in recent years, participated much more in their personal care plans, particularly those in the community. Patients who have been in a multidisciplinary environment, such as a hospice or in some day hospitals, will also have more experience of being involved in their own care. But that personal involvement is different from being part of a consultation group. Better methods of encouraging users to take part still need to be devised.

We need to explore ways of communicating information about illness, about available treatments, and about the probabilities of different outcomes in a manner which is friendly, informative, and non-directive and in a way which allows the patient to make a sensible choice of treatment. More research is needed of the effectiveness of different methods of communication to diverse groups of patients, which may include more innovative use of pictorial information and video recordings. Wennberg's group in the United States and others in the United Kingdom are 
exploring how patient choices are influenced by interactive video disks, in which patients can explore how previous patients have felt about relief of symptoms, the discomforts of the operation, and the occurrence of unwanted effects. ${ }^{48}$

The Patients Association informs us that healthcare professionals still determine treatment without adequate consultation with patients. For example, women with primary breast cancer with no nodal involvement are not always a choice between local excision of the tumour and mastectomy, which outcomes evidence would suggest would be appropriate. There is also widespread variation in practice whether or not axillary nodes are removed for staging purposes, ${ }^{4950}$ as recommended in guidelines published in $1986 . .^{51}$ Clinical practice is slow to change in response to research findings, ${ }^{52}$ and more research is needed on how best to influence professional actions. Many think that an attitudinal change is also necessary so that doctors are more responsive to the views of users of health services and of individual patients.

For true patient choice to be commonplace, there needs to be a concerted compaign on information and education, to alert patients to the fact that several options for treatment exist in many clinical disorders. In areas such as HIV/AIDS and breast cancer, patient groups tend to be relatively well informed. This is not so true, however, for many disorders. For patients with non-small cell carcinoma of the lung, for example, options vary between radiotherapy, chemotherapy, and surgery, or a combination of these. Indeed, the general practitioner's choice of consultant for first referral probably plays a large part in determining the treatment offered.

Users need to be involved in focus groups for single diseases or groups of conditions, working with clinicians in spelling out what matters and what does not, what is helpful and what is not. Several examples already exist in the United Kingdom. Patient participation groups meet in general practitioners' surgeries, and the research unit of the Royal College of Physicians has involved patient groups when determining guidelines for good practice for several clinical disorders (see reference 53). However, this is not the same as having groups of interested users in the majority and determining the issues they perceive to be of greatest importance. Such groups, if multiplied around the country, could play a major part in determining patient focused guidelines and also help monitor their use and their effect on patient care. Samples of users could be asked in telephone interviews about the kinds of services they would like to see and how they have felt about those that they have experienced. Such interviews would need to be designed by polling professionals alongside users, as would any written questionnaires.

Systematic work also needs to be done by professionals alongside focus groups on services such as physiotherapy, for which there is great demand from both patients and general practitioners. Perhaps healthcare scientists have adopted inappropriate models of efficacy. ${ }^{25}$

We also need to explore new ways of educating the public about the effectiveness and cost effectiveness of different procedures or treatments. We need to consider ways of helping users to appreciate their responsibilities as well as their rights. They need to be helped to take responsibility not only for helping to determine their own care but also for weighing up the effect that their decision will have on other members of society who may forgo treatment as a remote effect of that decision. Beyond personal choice, important though that is, is the public interest, and deciding priorities on behalf of a population. The most important role for users may be in public meetings called by purchasers to decide about resource allocation. Community health councils are central to this, and they need to set the agenda of debate. But other local figures may also have a role, such as local councillors, school governors, clergy, parish council members in rural areas, and those who work in health centres but are not necessarily healthcare professionals. We would add to such open consultation the possible benefit of direct election to purchasing authorities and boards of trusts to give them clear public accountability.

Hospitals, too, have a duty to their local users. Community health councils should suggest to trusts those services that they would particularly like to see audited. The councils themselves should be involved in the audit process, contributing knowledge that only they can have. It is not usually difficult to anonymise records sufficiently to make it acceptable for the councils to participate in the audit process and discuss issues that reflect the particular concerns of local users. Such proposals tend to be feared by health professionals, who fail to recognise that much of what they do can be assessed only by users or patients rather than by other healthcare professionals. A key element of an accountable service is to allow users into the decision making and audit processes.

Users of health services need to understand that not all current interventions are effective and that only through more research will we discover what works and what does not. It is therefore essential that users of health services are included in the audit process and participate in measuring outcomes of interventions. Users must be seen as partners in research and not as subjects. The results of any trial should include the impressions of the subjects, and they should be informed of the results. Users should also be consulted about future research protocols.

\section{Conclusion}

There is no lack of ways of including users far more in clinical decision making. The difficulty is in finding the courage to change the mould, to trust the users, to realise they have perceptions that no one else can have, and that they want to play a part. It should be possible to share information, discuss difficult issues, 
debate allocation of resources, and write practice guidelines which reflect the views of patients and their families. That way lies a better health service.

The Research Unit of the Royal College of Physicians is supported by generous grants from the Wolfson and Welton Foundations, the Help Medicine Appeal, other charitable donations, and the NHS Executive.

1 Donabedian A. Quality assurance in health care: consumers' role. Quality in Health Care 1992;1:247-51.

2 Joule N. Involving users of health care services: moving beyond lip service. Quality in Health Care 1993;2:211-2.

3 Rigge $M$. Involving patients in clinical audit. Quality in Health Care 1994;3(suppl):S2-5.

4 Donabedian A. Evaluating the quality of medical care Milbank Memorial Fund Quarterly 1966;44(suppl):166206.

5 Kaletsky A. Creating a citizen's market. The Times 1991 September 30 .

6 Mawhinney B, Nichol D. Purchasing for health: a framework for action. Leeds: NHS Management Executive, 1993 (Series of speeches.)

7 Pollock AM. Local voices: the bankruptcy of the democratic process. BMF 1992;305:535-6.

8 Brotchie J, Wann M. Training for lay participation in health: token voices or champions of the people. London: Patient Association, 1993.

9 NHS Management Executive. Local voices: the views of local people in purchasing health. Leeds: NHSME, 1992.

10 Davies P. Damned if they do, damned if they don't. Health Service fournal 1993:27 th May.

11 Association of Community Health Councils for England and Wales. Rationing health care. Can CHCs help? London: ACHEW, 1993 .

12 Ham C. Priority setting in the NHS: report from six districts. $B M \mathcal{F}$ 1993;307:435-8.

13 Patrick DK, Erickson P. Health status and health policy: quality of life in health care evaluation and resource allocation. Oxford: Oxford University Press, 1993.

14 Parry AJ, Giannopolous N, Ormerod O, Pillai R, Westaby $S$. An audit of cardiac surgery in patients over 70 years. QfM 1974;87:89-96.

15 Williamson C. Whose standards: consumer and professional standards in health care. Buckingham: Open University Press, 1992.

16 Expert Advisory Group on Cancer to the Chief Medical Officers of England and Wales. $A$ policy framework for commissioning cancer services. London: Department of commissioning

17 Berg J, Karlinsky H, Lowy F, eds. Alzheimer's disease research: ethical and legal issues. Toronto: Carswell, 1991.

18 Davies AR, Ware JE. Involving consumers in quality of care assessment. Health Affairs 1988;8:33-48.

19 Fitzpatrick R, Hopkins A. Patients' satisfaction with communication in neurological outpatient clinics. $f$ Psychosom Res 1981;25:329-34.

20 Fitzpatrick R, Hopkins A. Referrals to neurologists for headaches not due to structural disease. $\mathcal{f}$ Neurol Neurosurg Psychiatry 1981;44:1061-7.

21 Sox HC, Margulies I, Sox CM. Psychlogically mediated effects of diagnostic tests. Ann Intern Med 1981; 95:680-5.

22 David R, Enderby P, Bainton D. Treatment of acquired aphasia: speech therapists and volunteers compared. $f$ Neurol Neurosurg Psychiatry 1982;11:957-61.

23 Larsen EG, Omenn GS, Lewis H. Diagnostic evaluation of headache; impact of computerised tomography and costeffectiveness. $¥ A M A$ 1980;243:359-62.

24 Effective Health Care. Stroke rehabilitation. Leeds: University of Leeds, 1992.

25 Pound P, Bury M, Gompertz P, Ebrahim S. Views of survivors of stroke on benefits of physiotherapy. Quality in Health Care 1994;3:69-74.
26 Croog SH, Levine S, Testa MA, et al. The effects of hypertensive therapy on the quality of life. $N \mathrm{Engl} F \mathrm{Med}$ 1986;314:1657-64.

27 Garratt AM, Macdonald LM, Ruta DA, Russell IT, Buckingham JK, Krukowski ZH. Towards measurement of outcome for patients with varicose veins. Quality in of outcome for patients
Health Care 1993;2:5-10.

28 Hopkins A. How well are audit committees working? In Professional and managerial aspects of clinical audit. London RCP Publications, 1994:111-20

29 NHS Management Executive. Clinical audit in HCHS funding for 1994/95 and beyond. Leeds: NHSME, 1993 (EL(93) 104.)

30 Devlin HB. Audit and the quality of clinical care. Ann R Coll Surg Engl 1990; 72(suppl 1):3-14.

31 Richardson J, Stott R, Rentoul R. Gaining perspective. Health Service fournal 1990;100:435-7.

32 Sharma T. Patient voices. Health Service fournal 1992:Jan 20-1.

33 Rogers A, Pilgrim D, Lacey R. Experiencing psychiatry: users' views of services. London: Macmillan, 1993.

34 Rashid A, Forman W, Jagger C, Mann R. Consultations in general practice: a comparison of patients' and doctors' satisfaction. BMF 1989;299:1015-6.

35 Hares T, Spencer J, Gallagher M, Bradshaw C, Webb I. Diabetes care; who are the experts? Quality in Health Care 1992;1:219-24.

36 Taylor F, Ramsay M, Tan G, Renton A, Gabbay J. Evaluation of patients' knowledge about anticoagulan treatment. Quality in Health Care 1994;3:79-85.

37 McQuay HJ. Assessment of pain, and effectiveness of treatment. In: Hopkins A, Costain D, eds. Measuring the outcomes of medical care. London: RCP Publications, 1990:43-57.

38 Roter DL, Hall JA. Doctors talking with patients/patients talking with doctors: improving communication in medical visits. Westport, Connecticut and London: Auburn House, 1992 .

39 Hopkins A, Bahl V. Access to health care for people from black and ethnic minorities. London: RCP Publications, 1993.

40 First Seizure Trial Group. Randomized clinical trial on the efficacy of antiepileptic drugs in reducing the risk of prolapse after a first unprovoked tonic-clonic seizure. Neurology 1993;43:478-83.

41 Gritzner C. The CASPE patient satisfaction system. In Hopkins A, Fitzpatrick R, eds. Measurement of patients satisfaction with their care. London: RCP Publications, 1993:33-41.

42 Hjortdahl P, Laerum E. Continuity of care in genera practice: effect on patient satisfaction. $B M F 1992$ 304:1287-90.

43 Wennberg JE, Freeman JL, Culp WJ. Are hospital services rationed in New Haven or over-utilised in Boston? Lancet 1987; i:1185-9.

44 Roland M, Coulter A. Hospital referrals. Oxford: Oxford University Press, 1992

45 Being heard: report of a review committee on NHS complaints procedures. London: Department of Health, 1994.

46 General Medical Council. Proposals for new performance procedures. London: GMC, 1992. (Consultation paper.)

47 Royal Colleges of Physicians of Edinburgh, Glasgow and London. Continuing medical education. London: RCPEd, RCPGlas, RCPLond, 1994.

48 Fowler FJ, Wennberg JE, Timothy RP, et al. Symptom status and quality of life following prostatectomy. $\mathcal{F} A M A$ 1988;259:3018-22.

49 Chouillet AM, Bell CMJ, Hiscox JG. Management of breast cancer in southeast England. BMF 1994;308:168-71.

50 Working Party of the British Breast Group. Provision of breast services in the UK: the advantages of specialist breast units. London: British Breast Group, 1994.

51 King's Fund. Consensus development conference: treatment of primary breast cancer. $B M \mathcal{F} 1986$ 293:946-7.

52 Lau J, Antman EM, Jiminez-Silva J, Kupelnick B, Mosteller F, Chalmers TC. Cumulative meta-analysis of therapeutic trials for myocardial infarction. $N$ Engl f Med therapeutic trials

53 Guidelines for good practice in the diagnosis and treatment of non-insulin-dependent diabetes mellitus. $f R C o l l$ Physicians Lond 1993;27:259-66. 